\title{
Leptomeningeal Sarcoma
}

National Cancer Institute

\section{Source}

National Cancer Institute. Leptomeningeal Sarcoma. NCI Thesaurus. Code C8312.

A sarcoma arising from the leptomeninges. 